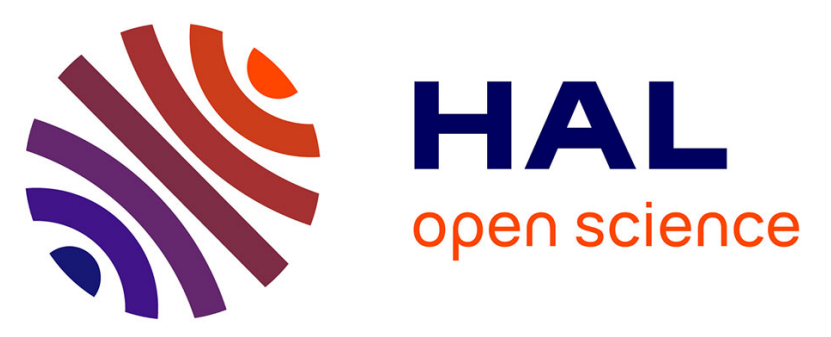

\title{
Post-Weld Heat Treatment of Additively Manufactured Inconel 718 Welded to Forged Ni-Based Superalloy AD730 by Linear Friction Welding
}

Seyedmohammad Tabaie, Farhad Rezai-Aria, Bertrand C.D. Flipo, Jonathan Cormier, Mohammad Jahazi

\section{To cite this version:}

Seyedmohammad Tabaie, Farhad Rezai-Aria, Bertrand C.D. Flipo, Jonathan Cormier, Mohammad Jahazi. Post-Weld Heat Treatment of Additively Manufactured Inconel 718 Welded to Forged NiBased Superalloy AD730 by Linear Friction Welding. Metallurgical and Materials Transactions A, 2021, 52A, pp.3475-3488. 10.1007/s11661-021-06319-0 . hal-03251491

\section{HAL Id: hal-03251491 https://imt-mines-albi.hal.science/hal-03251491}

Submitted on 20 Sep 2021

HAL is a multi-disciplinary open access archive for the deposit and dissemination of scientific research documents, whether they are published or not. The documents may come from teaching and research institutions in France or abroad, or from public or private research centers.
L'archive ouverte pluridisciplinaire HAL, est destinée au dépôt et à la diffusion de documents scientifiques de niveau recherche, publiés ou non, émanant des établissements d'enseignement et de recherche français ou étrangers, des laboratoires publics ou privés. 


\title{
Post-Weld Heat Treatment of Additively Manufactured Inconel 718 Welded to Forged Ni-Based Superalloy AD730 by Linear Friction Welding
}

\author{
SEYEDMOHAMMAD TABAIE, FARHAD RÉZAÏ-ARIA, BERTRAND C.D. FLIPO, \\ JONATHAN CORMIER, and MOHAMMAD JAHAZI
}

\begin{abstract}
A new post-weld heat treatment (PWHT) cycle was designed for novel dissimilar linear friction welding (LFW) of selective laser melted (SLM) Inconel 718 (IN718) to AD730 forged nickel-based superalloy. The microstructure and hardness of the joints after the PWHT are investigated and compared with those of as-linear friction welded samples. The precipitation of $\gamma^{\prime}+\gamma^{\prime \prime}$ is determined as the main mechanism to increase the mechanical properties of SLM IN718 alloy. These particles coarsened during heat treatment at $1253 \mathrm{~K}$ and double aging. The results show that the thermomechanical history of linear friction welded joints can affect the microstructure of IN718 alloy such as the morphology of $\delta$ phase after solution treatment (ST) from the platelike in the weld zone (WZ) to the needlelike in the base material (BM). It was found that in AD730, nanometric size $\gamma^{\prime}$ particles reprecipitated close to the weld line during rapid cooling after welding. The presence of ultrafine $\gamma^{\prime}$ particles and coarsening of the remaining particles in the microstructure of the alloy, during PWHT, can enhance the strength and hardness. The developed PWHT resulted in uniform hardness across the new dissimilar joint.
\end{abstract}

\section{INTRODUCTION}

LINEAR friction welding (LFW) is a solid-state welding technique that overcomes defects induced by fusion welding methods. This technique is very fast and flexible and has recently been applied for the manufacturing and repair of blade integrated disks (blisks) in the aerospace industry as well as in other turbine applications. ${ }^{1-4]}$ Alloys used for such applications are made of precipitation-hardened nickel (Ni)-based superalloys. Due to the large volume fraction of the second-phase particles in these alloys, they are susceptible to crack

SEYEDMOHAMMAD TABAIE and MOHAMMAD JAHAZI are with the Department of Mechanical Engineering, École de technologie supûrieure (ETS), H3C 1K3 Montreal, QC, Canada. Contact email: Mohammad.jahazi@etsmtl.ca FARHAD RÉZAïARIA is with the Institut Clû̀ment Ader (ICA), Université de Toulouse, CNRS, IMT Mines Albi, INSA, UPS, ISAE, Campus Jarlard, 81013 Albi, France. BERTRAND C.D. FLIPO is with TWI Ltd, Granta Park, Great Abington, Cambridge CB21 6AL, United Kingdom. JONATHAN CORMIER is with Institut Pprime, UPR CNRS 3346, Dûpartement de Physique et Mécanique des Matériaux, ISAE-ENSMA，BP 40109, 86961 Futuroscope-Chasseneuil Cedex, France. formation. The latter could occur in both the weld zone (WZ) and the heat-affected zone (HAZ) during welding or post-weld heat treatment (PWHT).$^{[1,5,6]}$ Formation of intergranular liquation cracking, microshrinkage, strain-age cracking associated with melting and solidification, and PWHT are the main reasons why newly designed Ni-based superalloys $\left(\gamma^{\prime}\right.$ volume fraction of more than $40 \mathrm{pct}$ ) are categorized as "unweldable" alloys by conventional fusion welding techniques. ${ }^{[1,7]}$

Selective laser melting (or laser powder bed fusion) is one of the main additive manufacturing (AM) techniques. AM presents significant advantages compared to conventional methods, such as forging, by reducing the number of fabrication steps and the manufacturing of parts with complex geometry. ${ }^{[8-10]}$ The microstructure of fabricated parts contains inhomogeneity in the fraction of precipitates arising from the high thermal gradient of the parts during fabrication. Any inhomogeneity can be controlled by applying different post-heat-treating cycles. However, such PWHT may not be enough to erase tailored microstructure buildup. ${ }^{[9,11-16]}$

As reported in Reference 17 developing a hybrid technique (SLM + LFW) involves some difficulties such as controlling and tailoring the microstructure of the alloy after SLM and after joining. A number of research 
studies $^{[7,18-22]}$ have reported that changes in the microstructure of the as-linear friction welded alloy take place that can affect the chemical composition, grain sizes, and strengthening phases, and can induce undesirable eutectic compounds and liquation. The preceding changes could result in different mechanical properties such as hardness in different regions. Hence, to enhance the microstructure stability and to tackle undesirable variation in hardness and residual stresses, a PWHT cycle is required. ${ }^{[1,23-27]}$

The high-temperature exposure and high heating (400 $\mathrm{K} / \mathrm{s}$ to $500 \mathrm{~K} / \mathrm{s})$ and cooling $(150 \mathrm{~K} / \mathrm{s}$ to $250 \mathrm{~K} / \mathrm{s})$ rates present in the LFW process led to smaller average particle sizes and volume fraction of secondary phases, resulting in hardness reduction in the $\mathrm{WZ}$ in comparison to the base material (BM). ${ }^{[28,29]}$ Qin et al. ${ }^{[30]}$ simulated the heat generated during LFW of superalloys and its impact on the temperature and plastic deformation behavior of the alloy. Their simulated results were validated by microstructure observation, which showed the influence of plastic deformation heat on phase transformation. In the case of the friction welding of dissimilar superalloys, ${ }^{[7,22]}$ the significant differences existing between the microstructures, particularly in terms of the type and the volume fraction of the strengthening phase $\left(\gamma^{\prime} / \gamma^{\prime \prime}\right)$ and grain size, could make it particularly difficult to attain a sound dissimilar joint. Roder et al. ${ }^{[31]}$ reported on tensile tests on IN718 alloy inertia friction welded to INCOLOY* 909 at different

* INCOLOY and IN are trademarks of Special Metals Corporation, New Hartford, NY.

temperatures. In these tests, failure occurred in the WZ of IN718 alloy due to the absence of $\gamma^{\prime \prime}$ strengthening precipitates. However, regarding the LFW of AD730,**

**A730 is a trademark of Aubert \& Duval, Paris, Île-de-France

Masoumi et al. ${ }^{[18,32]}$ revealed that failure and crack initiated in the BM and a final fracture occurred in the zone adjacent to the thermomechanical affected zone (TMAZ) during tensile testing at room temperature. They reported that the observed higher strength of the WZ as compared to that of the TMAZ resulted from finer grain microstructure and reprecipitation of fine secondary phase in the WZ. The $y^{\prime}$ particles (30 to 200 $\mathrm{nm})$ reprecipitated in the $\mathrm{WZ}^{[33,34]}$ at a higher proportion than did those of the TMAZ and the BM during cooling after LFW. They noted that the PWHT cycle led to $\gamma^{\prime}$ reprecipitation in the TMAZ and restored the tensile properties of the linear friction welded samples. ${ }^{[18]}$

Smith et al. ${ }^{[35,36]}$ reported that the PWHT of linear friction welded IN718 samples improved the hardness and tensile properties (at room temperature) of the weldment, likely partially due to an increase in the volume fraction of $\gamma^{\prime \prime}$ phase resulting from complete $\delta$ phase dissolution. It was observed that the PWHT resolutionized the $\delta$ phase uniformly even when the starting materials varied significantly in terms of $\delta$ phase volume fraction. Therefore, applying the PWHT on linear friction welded samples was compatible. Chaturvedi $^{[37]}$ and Chaturvedi and $\operatorname{Han}^{[38]}$ reported that the precipitate strengthening mechanisms in IN718 varied (changing between precipitate shearing and coherency strain strengthening mechanisms) based on the size, morphology, and volume fraction of the primary strengthening precipitates (i.e., spheroidal $\gamma^{\prime}$ and ellipsoidal $\gamma^{\prime \prime}$ ), which were highly influenced by the aging duration and heat treatment peak temperature. In many studies, ${ }^{[26,39-41]}$ in the case of cast and wrought or AM IN718, the dissolution of strengthening precipitates and their coarsening and the formation of $\delta$ phase are microstructure evolutions that have been shown to play crucial roles in the decline of mechanical properties such as fatigue life, stress-rupture life, creep resistance, and tensile strength. ${ }^{[42]}$ Damodaram et al. ${ }^{[2]}$ reported that $\gamma$ "' particles dissolved in the WZ and the HAZ. Due to coarser grains in the HAZ, this zone was weaker than the WZ; therefore, failure occurred in the HAZ. However, post-weld heat treated samples (solution-treated (ST) and ST + aged (STA)) failed in the BM. The STA sample after welding exhibited the best stress-rupture properties. The authors explained that this could be attributed to the moderate coarsening of the grains at the WZ induced by homogenization.

Selective laser melting can be designed and combined with the LFW process as a developing welding process to create and to accelerate the manufacture or repair of blisks with dissimilar alloys. The main objective of the present study was to develop new and specific PWHT cycles for novel linear friction welded dissimilar joints of polycrystalline Ni-based superalloy AD730 to as-SLM IN718 and to homogenized SLM IN718 (H-SLM IN718). Therefore, a comparative study between as-linear friction welded and PWHT states was carried out to investigate the relationship of heat treatment, microstructural characteristics, and hardness. The obtained hardness measurements are compared with other reported results in the literature.

\section{EXPERIMENTAL PROCEDURES}

\section{A. Post-Weld Heat Treatment}

The as-received forged AD730 alloy, provided by Aubert \& Duval, had an average grain size of $41.36 \pm$ $9.14 \mu \mathrm{m}$ and a volume fraction of $\gamma^{\prime}$ of 40 pet (for all $\gamma^{\prime}$ classes). SLM-125HL AM equipment, at IMT-Mines Albi in France, was used to fabricate IN718 superalloy. Samples were fabricated in the $Z$-direction, which is perpendicular to the fabrication platform for LFW conditions. Two rectangular AD730 samples (37-mm length $\times 26-\mathrm{mm}$ width $\times 13-\mathrm{mm}$ height) were linear friction welded to an as-SLM IN718 and an H-SLM IN718 (homogenized at $1373 \mathrm{~K}$ for 1 hour and water quenched) with the same dimensions. Their chemical compositions are provided in Table I. 
The FW34-E20 LFW machine at TWI Ltd was used for the LFW process in this investigation. The following process parameters were used to produce welded specimens: friction pressure of $228 \mathrm{MPa}$, oscillation frequency of $40 \mathrm{~Hz}$, amplitude of $3 \mathrm{~mm}$, and forge pressure of $340 \mathrm{MPa}$ as the last step of the LFW. The oscillation displacement occurred perpendicular to the SLM building direction and on the top part of the SLM samples. Therefore, the contact surface in the AD730 was in touch with the top of the SLM fabricated simples. Three welds were post-weld heat treated in this study: two as-SLM IN718-AD730 (W1) and one as H-SLM IN718-AD730 (W2).

Figure 1 shows the PWHT cycle used in the present investigation. Depending on the microstructure of the SLM IN718 and the precipitation hardening treatment for the IN718 and AD730 alloys, one of the samples of W1 was ST at $1253 \mathrm{~K}$ for 1 hour and water quenched. It should be noted that the solution treatment heat treatment is for IN718 alloy. The samples were subsequently aged at $1003 \mathrm{~K}$ for 12 hours, cooled in the furnace $(55 \mathrm{~K} / \mathrm{h})$, and held at $893 \mathrm{~K}$ for 10 hours, followed by air cooling (W1-STA). The second sample of $\mathrm{W} 1$ and the W2 sample were directly aged and are identified as W1-DA and W2-DA, respectively. Regarding the industrial aging treatment of AD730 alloy at $1003 \mathrm{~K}$ to $1033 \mathrm{~K}$ for 8 to 10 hours and the first aging step of SLM IN718 alloy at $993 \mathrm{~K}$ to $1033 \mathrm{~K}$ for 8 to 10 hours, in this study, the temperature and time of the first aging step (for dissimilar welds) are modified (i.e., temperature $1003 \mathrm{~K}$ and time change from 8 to 12 hours). It should be noted that the second aging step (893 K for 10 hours) cannot affect the precipitation hardening in AD730. However, the time was increased from 8 hours (the usual aging time for IN718 alloy) to 10 hours to compare the results with the literature.

\section{B. Microstructure Analysis}

The as-linear friction welded samples were cross sectioned by electrical discharge machining (EDM) from the center of the welded samples along the longitudinal axis and perpendicular to the welding direction. The waterless Kalling and Marble solutions were used to reveal the microstructural features, which were examined using a tabletop scanning electron microscope (SEM) (Hitachi TM3000) and a field emission-SEM (FESEM) (Hitachi SU-8230) (Japanese

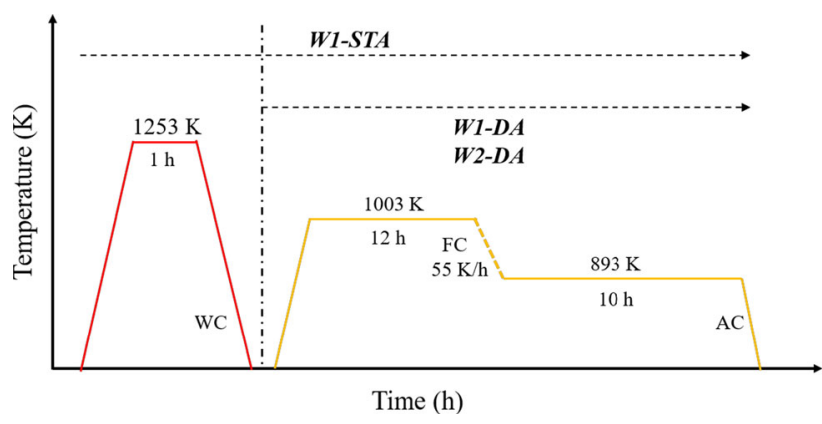

Fig. 1-Schematic of the PWHT cycle for all linear friction welded samples.

Multinational Engineering and the Electronics Conglomerate Company, Tokyo, Japan). Furthermore, a Quad energy-dispersive X-ray spectroscopy (EDS) detector and a Bruker electron backscatter diffraction (EBSD) detector were also used in the analysis.

For EBSD investigation, samples were polished using a Buehler VIBROMET (Illinois, USA) with colloidal silica suspension $(0.05 \mu \mathrm{m})$ and then an ion beam milling system (IM 400Plus, Hitachi) for optimum surface preparation and removal of any subsurface damage during the polishing stages. For regions close to the weld lines (or WZ), where very fine recrystallized grains could be present, a fine step size of $90 \mathrm{~nm}$ was used. The nonrecrystallized regions were examined by a coarser step size of $0.47 \mu \mathrm{m}$. At least 300 grains were characterized for each region.

\section{Microhardness Test}

The Vickers microhardness (HV) profile was measured on cross-sectioned post-weld heat treated samples throughout the weldment by using an automatic Future-Tech Vickers machine. The obtained results were compared with as-linear friction welded samples (W1 and W2). A load of $200 \mathrm{~g}$ (HV0.2) and a dwell time of 15 seconds were employed for all measurements from the weld interface toward the BM (a distance of $\sim 3$ $\mathrm{mm}$ ). The hardness examination was conducted on both linear friction welded and post-weld heat treated samples. The measurements were repeated between three and five times for different distances. The average values are reported with errors between 0.4 pct (in the WZ and the BM) and 2.1 pet (in the TMAZ).

Table I. Chemical Compositions of the Bulk of Alloys (Weight Percent)

\begin{tabular}{|c|c|c|c|c|c|c|c|c|c|c|c|c|c|}
\hline \multirow[b]{2}{*}{ Alloy } & \multicolumn{13}{|c|}{ Elements } \\
\hline & $\mathrm{Ni}$ & $\mathrm{Fe}$ & $\mathrm{Cr}$ & $\mathrm{Co}$ & Mo & W & $\mathrm{Al}$ & $\mathrm{Ti}$ & $\mathrm{Nb}$ & B & $\mathrm{C}$ & $\mathrm{Zr}$ & $\mathrm{Si}$ \\
\hline Forged AD730 & bal & 4.00 & 15.70 & 8.50 & 3.10 & 2.70 & 2.25 & 3.40 & 1.10 & 0.010 & 0.015 & 0.030 & - \\
\hline SLM IN718 & bal & 15.70 & 20.54 & 0.10 & 3.13 & - & 0.34 & 1.17 & 5.10 & 0.002 & 0.040 & 0.018 & 0.01 \\
\hline
\end{tabular}




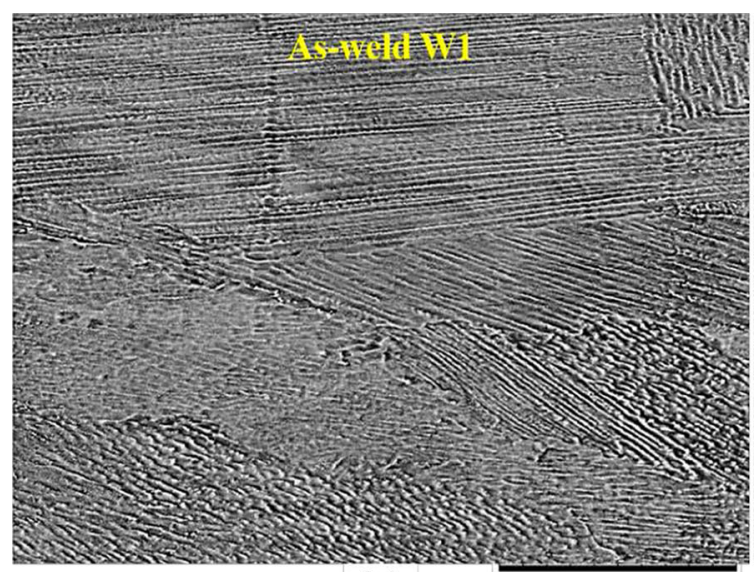

(a)

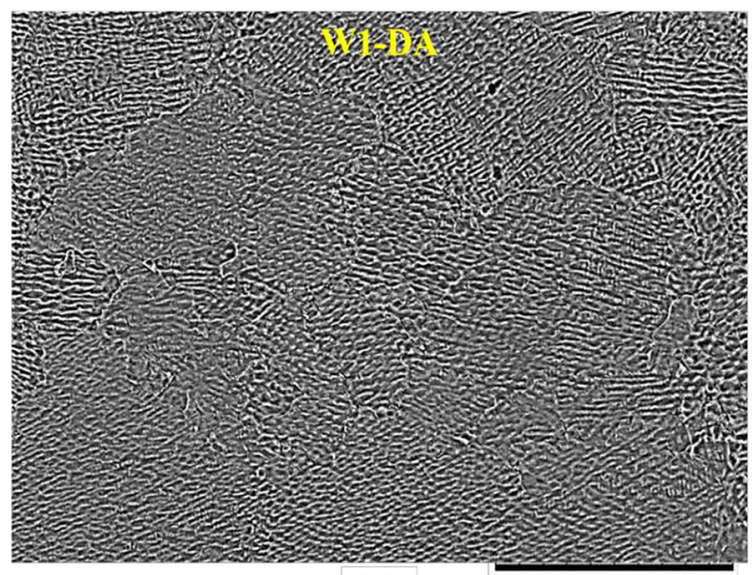

(c)

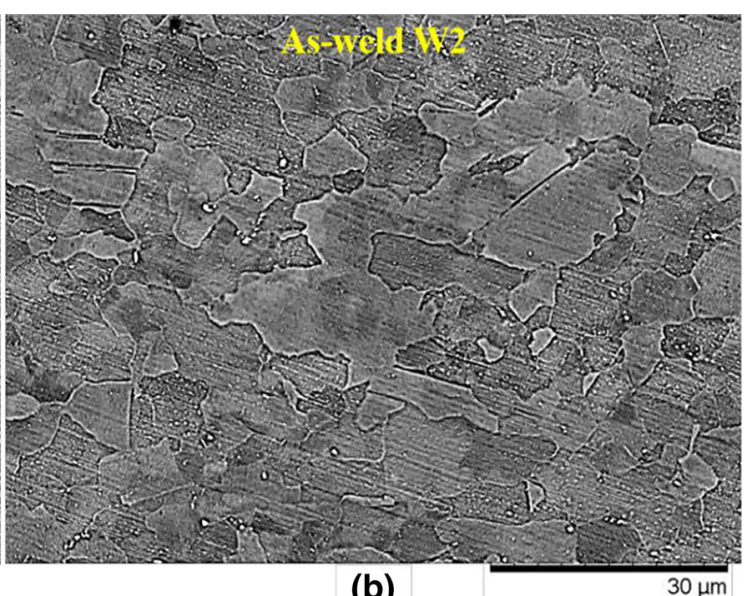

(b)

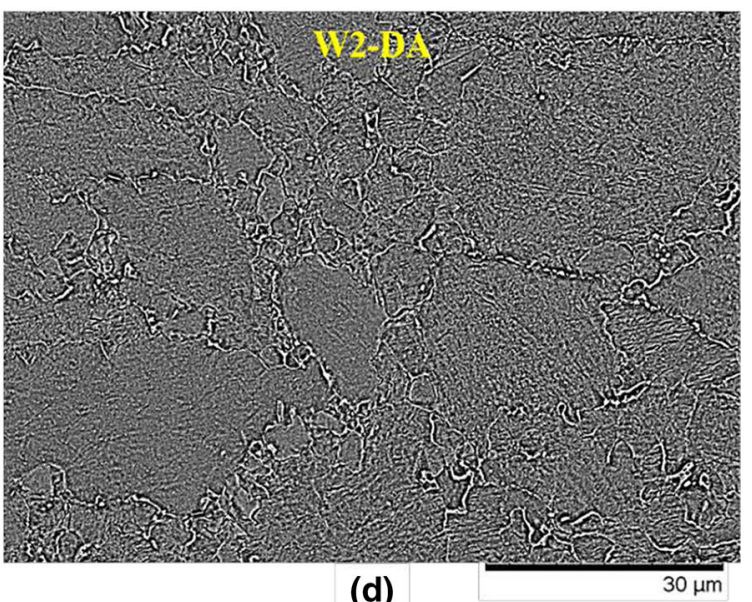

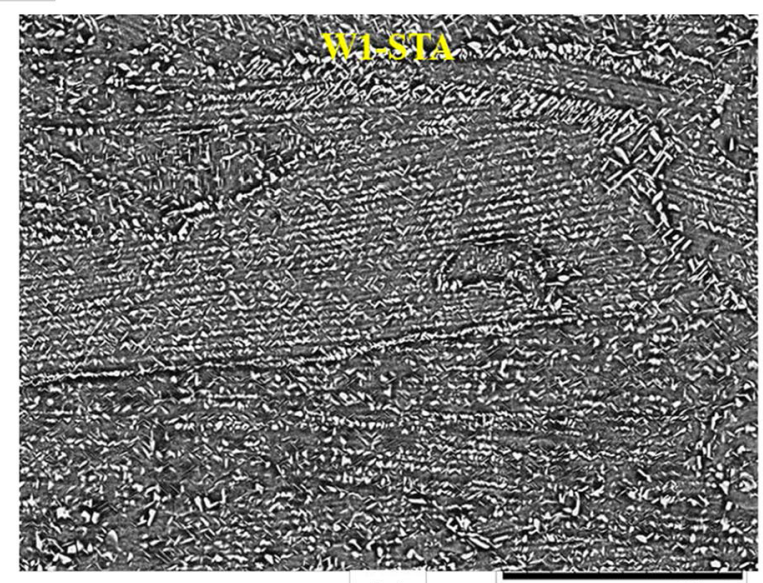

(e)

$30 \mu \mathrm{m}$

Fig. 2-SEM micrograph in the BM zone of IN718 alloy after LFW and PWHT for $(a)$ W1, (b) W2, (c) W1-DA, (d) W2-DA, and (e) W1-STA.

\section{RESULTS AND DISCUSSION}

\section{A. Microstructure Evolution}

Figures 2(a) through (d) show illustrative examples of different samples in the as-welded or post-weld heat treated conditions. The results show that no grain growth has occurred in SLM IN718 after the DA due to the prevailing low temperature (maximum $1003 \mathrm{~K}$ ).
However, in the W1-STA IN718 sample, the columnar grains partially recrystallized due to the 1-hour heat treatment at $1253 \mathrm{~K}$ before aging, resulting in a slight decrease in the average grain size in the $\mathrm{BM}$ (Figure 2(e)). It should be noted that the columnar grains and cellular structures, characteristic of the as-fabricated microstructure, were retained in the microstructures of the SLM IN718 (in the BM of 


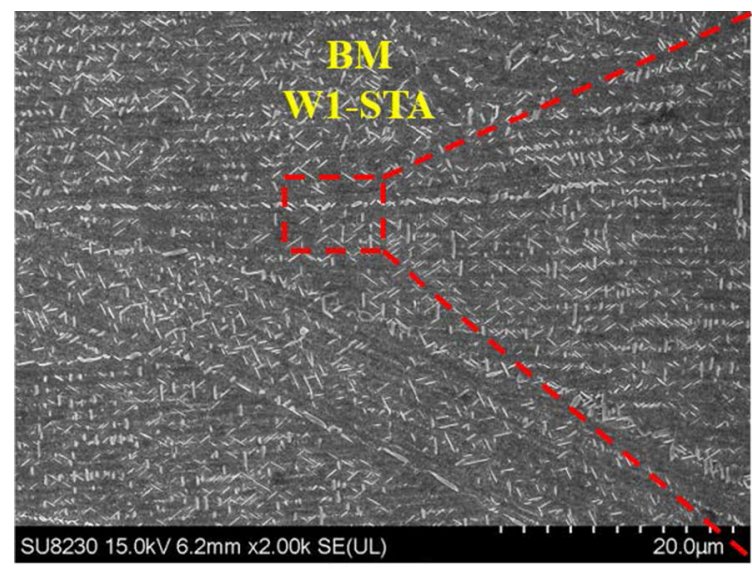

(a)

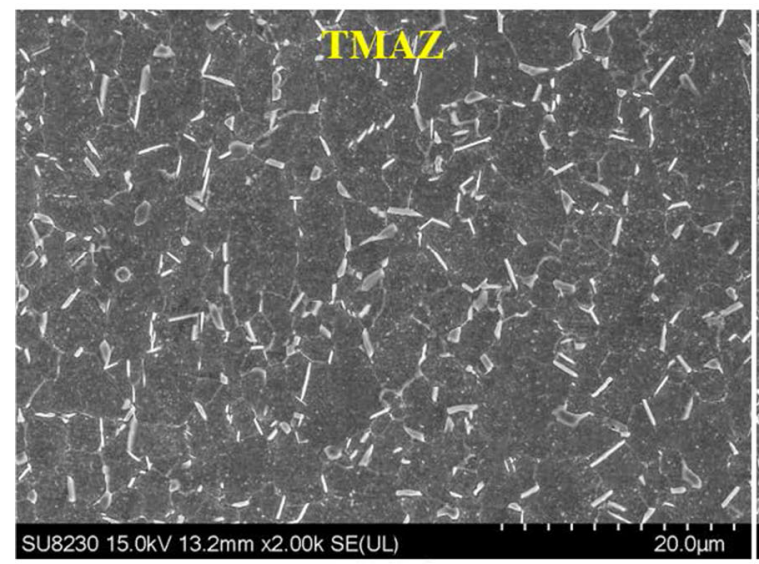

(c)

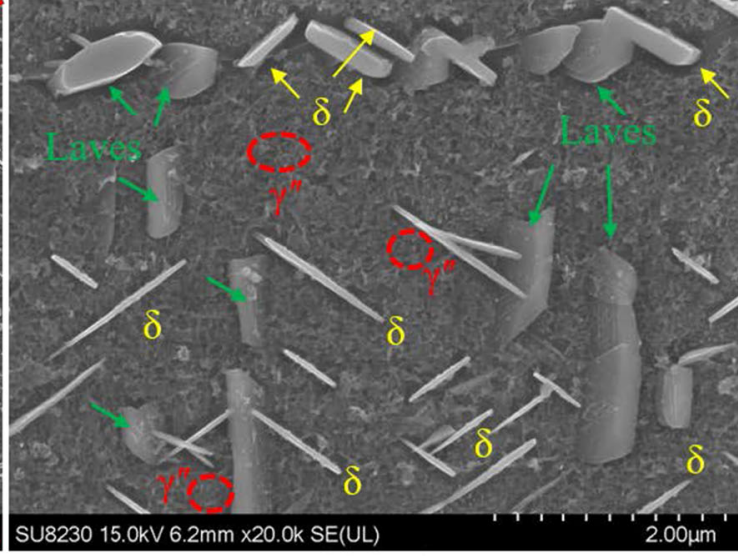

(b)

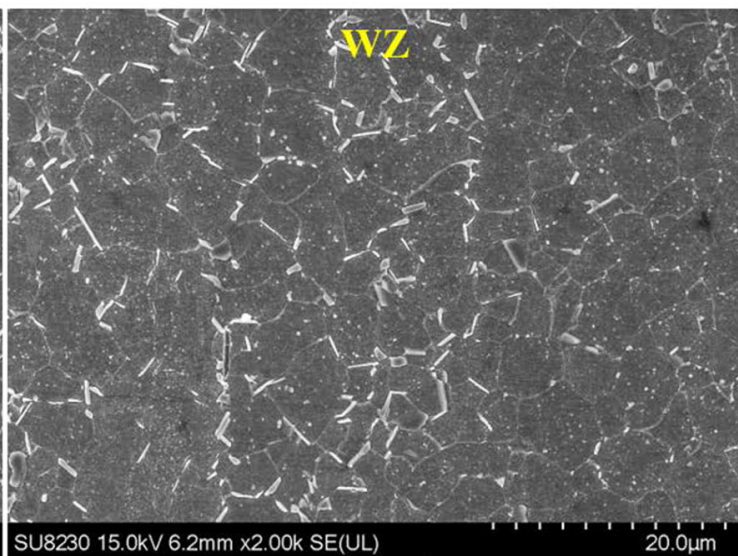

(d)

Fig. 3-SEM images from sample W1-STA on the side of the SLM IN718 alloy in the (a) BM, (b) intergranular and intragranular $\delta$ phase at the BM, (c) TMAZ, and (d) WZ.

W1-STA) specimen (Figures 2(a) and (c)). In the W2-DA (Figure 2(d)), the as-fabricated microstructure, the columnar grains, and the cellular structures were partially removed after homogenization (before LFW) and replaced with equiaxial grains; however, a highly oriented structure could be observed inside the grains. $\mathrm{Ni}$ et $a .^{[13]}$ reported that partial recrystallization is beneficial in decreasing the anisotropy for mechanical properties. However, on AD730, no grain size change was observed since $1253 \mathrm{~K}$ was too low a temperature to induce any grain growth or recrystallization. ${ }^{43,44]}$

As shown in Figures 2 and 3, in addition to grain size, different types of secondary phases precipitated after PWHT in different regions. Figure 3 shows the evolution of the shape, location, and volume fraction $\left(V_{f}\right)$ of the $\delta$ phase in IN718 alloy (W1-STA) from the BM zone to the WZ. In the BM, two $\delta$-phase morphologies were observed, i.e., intragranular needlelike and platelike $\delta$ phases at grain boundaries (intergranular) in the vicinity of granular and long-striped Laves particles ( $\mathrm{Nb}$ : 21.58, Mo: 1.88, Ti: 1.77 (at. pct), on average). The presence of $\delta$ phase particles (Nb: 9.92, Mo: 1.74, Ti: 1.75 (at. pct), on average) of varied sizes can be observed within the grains (larger) and at grain boundaries (smaller). Furthermore, the dimensions (e.g., length and width) of the $\delta$ particles increased from the BM to the WZ. This evolution was also observed in the microstructures of W1-DA and W2-DA on the IN718 side, where the fraction of the $\delta$ phase was less than that of W1-STA (Figure 4). As shown in Figure 4, $\delta$ particles are larger and platelike or semispherical in the $\mathrm{WZ}$ and in the TMAZ (from the weld interface to $\sim 1700 \mu \mathrm{m}$ ).

On the IN718 side, due to the heat treating at $1253 \mathrm{~K}$ and aging on W1-STA, the microstructure contains more $\delta$ phase within the grain and at the grain boundaries. Moreover, in the BM, this phase experienced greater $\delta$ precipitation than in the TMAZ and the WZ (Figures 3 and 4).

The $\delta$ phase formed in the segregated regions (interdendritic) where the Laves phase (enriched $\mathrm{Nb}$ ) precipitated after fabrication and solidification, but not so in the core of dendrites having a low content of $\mathrm{Nb}$. This indicates that the formation of this phase is a function of $\mathrm{Nb}$ local concentration. ${ }^{[4]}$ Since the amount and size of the $\delta$ phase depends on the thermomechanical history of the alloy, ${ }^{[30]}$ the dissolution and precipitation of platelike and spherical $\delta$ phase particles both occurred during the deformation ${ }^{[46]}$ and underwent a transformation during the thermomechanical process such as the one in LFW (Figure 4). The level of deformation during the 


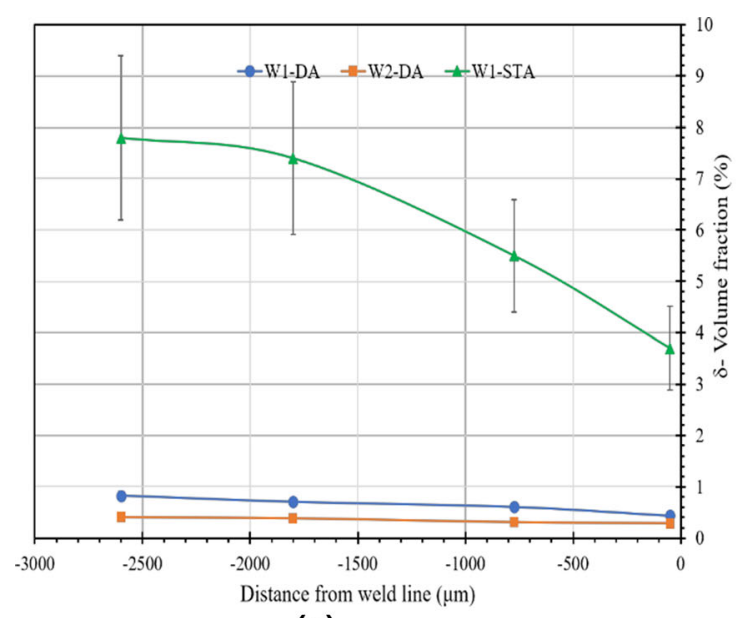

(a)

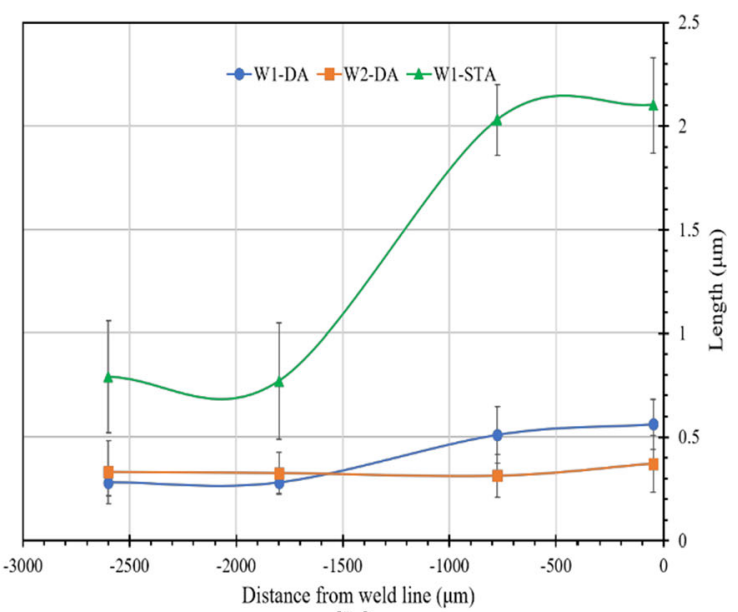

(b)

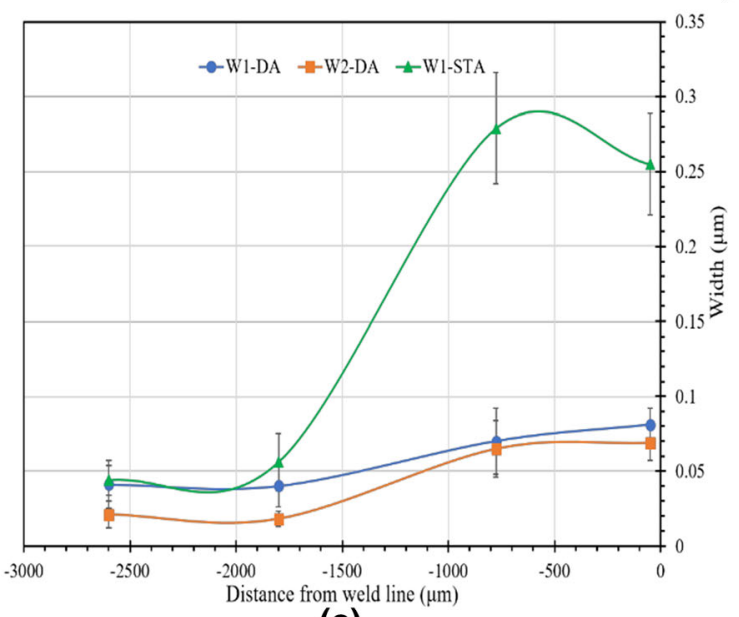

(c)

Fig. 4 - Size and volume fraction $\left(V_{f}\right)$ evolution of the $\delta$ phase from the WZ toward the BM, on the SLM IN718 side, in different samples after PWHT: $(a)$ volume fraction, $(b)$ length, and $(c)$ width of $\delta$ particles.

LFW decreases from the WZ to the BM.$^{[47,48]}$ As shown in Figure 4(a), the volume fraction of $\delta$ phase increased from the $\mathrm{WZ}$ to the $\mathrm{BM}$ in all samples. As a result of deformation and dissolution (due to the higher temperature close to the weld line), the platelike $\delta$ phase that had been formed during the SLM process (and before STA) in grain boundaries was transformed, as precursor, dissolved/transformed into short granular rods or semispherical $\delta$ phase particles (Figures 4(b) and (c)). The other platelike particles could be formed during the ST. ${ }^{[49]}$

As also reported previously, ${ }^{[17,50]}$ there is an evolution in size, shape, and volume fraction of precipitates, from the WZ to the BM, on both sides. Figures 5(a) and (b) show the microstructure in the WZ in the W1 and W1-DA samples, on the AD730 side, before and after the PWHT, respectively.

In the $\mathrm{WZ}$, on the AD730 side, the $\gamma^{\prime}$ phase was completely dissolved during LFW. Figure 5(a) shows no secondary phase precipitates close to the weld line after welding. However, the ultrafine $\gamma^{\prime}$, which could have reprecipitated due to the high cooling rate after LFW, were coarsened (primary $\gamma^{\prime}$ ) or newly precipitated (secondary + tertiary $\left.\gamma^{\prime}\right)(44 \pm 12.2 \mathrm{~nm})$ within grains (as well as W2-DA sample) (Figure 5(c) and (d)) after the PWHT. In W1-STA, $\gamma^{\prime}$ particles are larger $(189 \mathrm{~nm}$ \pm 29 ) due to the heat treatment (or ST) before aging (Figure 6). The heat treatment temperature (1253 K) used for W1-STA is less than the solvus temperature of the $\gamma^{\prime}$ phase $(\sim 1378$ to $1383 \mathrm{~K})$ and of secondary $\gamma^{\prime}$ particles $(1323$ to $1353 \mathrm{~K})$ in a fine grain AD730. ${ }^{[33,51]}$ Therefore, on the AD730 side, fine secondary $\gamma^{\prime}$ dissolved during the heat treatment at $1253 \mathrm{~K}$, while undissolved or large particles coarsened, potentially affecting the volume fraction of $\gamma^{\prime}$ in the microstructure (from $\sim 160 \mathrm{~nm}$ in W1-DA to $\sim 250 \mathrm{~nm} \mathrm{W1-STA}$ at the $\mathrm{BM})$. The variation of the volume fraction and the size of $\gamma^{\prime}$ in AD730 is provided in Figure 7 for W1-DA and W1-STA. It should be noted that primary $\gamma^{\prime}$ was not observed in the WZ of the samples (Figure 5(a) and (b) and Figure 6(a)), and the $V_{f}$ is reported for all categories.

Due to the temperature gradient between the $\mathrm{WZ}$ and the BM during LFW, almost all of the $\gamma^{\prime}$ dissolved in the WZ, where the temperature had reached $1473 \mathrm{~K}$ to 1523 $\mathrm{K}$, and $\gamma^{\prime}$ primary and secondary were partially dissolved in the TMAZ, where the temperature had reached $1173 \mathrm{~K}$ to $1373 \mathrm{~K}$. After PWHT (DA), ultrafine 


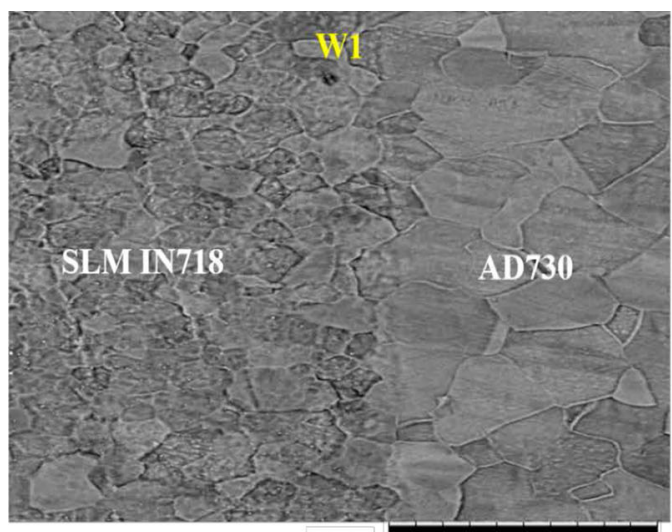

(a)

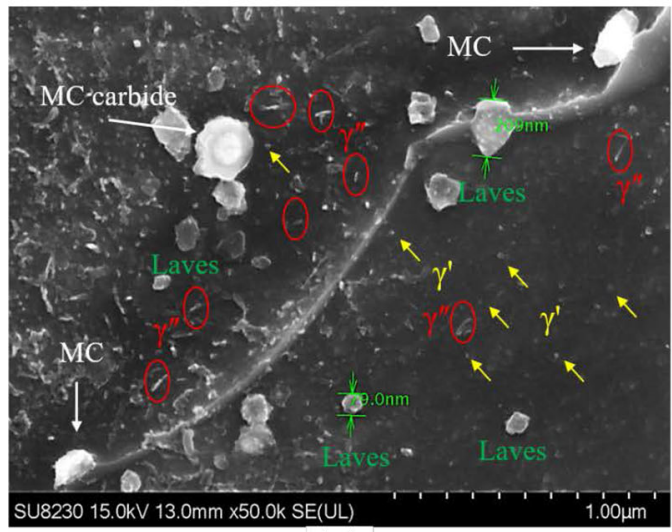

(c)

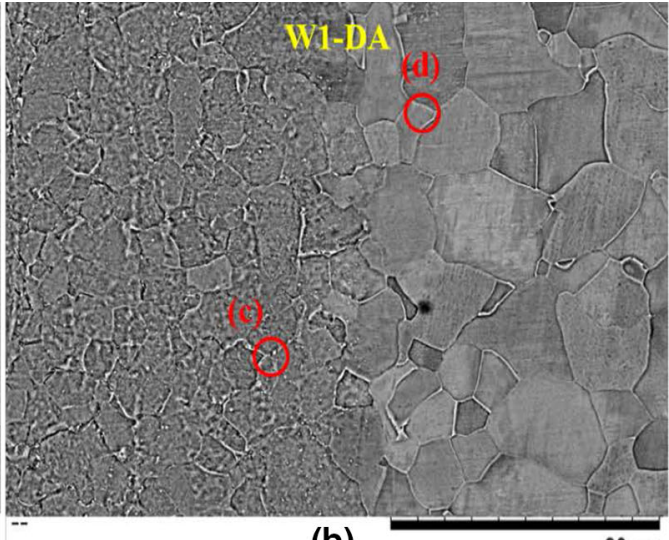

(b)

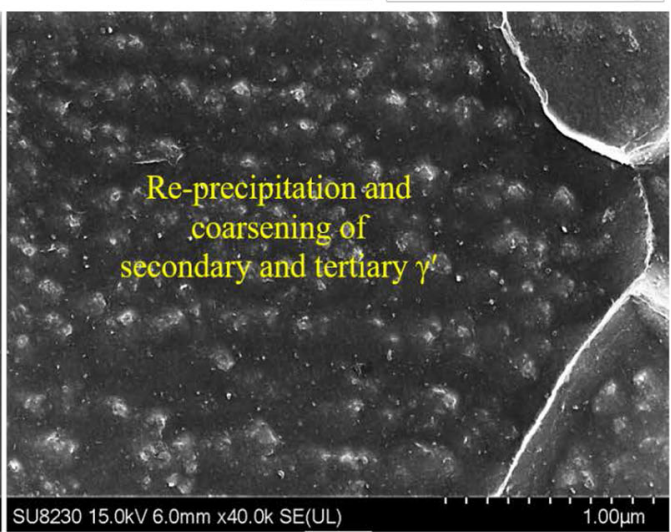

(d)

Fig. 5-Precipitation of secondary phases in the weld interface of W1 sample after PWHT: $(a)$ as-linear friction welded, (b) W1 direct aged, $(c)$ on the DA-SLM IN718 side in the WZ, and $(d)$ very fine secondary and probably tertiary $\gamma^{\prime}$ in DA-AD730 in the WZ.

$\gamma^{\prime}\left(2\right.$ to $\left.10 \mathrm{~nm}^{[18,33]}\right)$ remained in the $\mathrm{WZ}$ of as-linear friction welded samples (in AD730), coarsened slowly during the first step of DA at $1003 \mathrm{~K}$ (for 12 hours) in W1-DA and W2-DA samples. It must be noted that these particles could be reprecipitated and further coarsened (by 3 times close to the $\mathrm{WZ}$ and by 1.6 times in the BM) during the heat treatment at $1253 \mathrm{~K}$ and during double aging (W1-STA). However, the ST time and temperature are not long enough for the precipitation of primary $\gamma^{\prime}$, although comparing W1-STA with W1-DA shows that it was coarsened, as shown in Figure 7(b). According to the Lifshitz-Slyozov-Wagner (LSW) equation, ${ }^{[52]}$ which describes the growth kinetics of the $\gamma^{\prime \prime} / \gamma^{\prime}$ precipitate, these precipitates coarsen gradually with aging time. ${ }^{[53,54]}$ As also reported in References 5, 55 and 56 on the AD730 side, the shape of the $\gamma^{\prime}$ precipitate could change from spherical to quasi-spherical and cubic (more rounded edges) as a result of coarsening that occurs during heat treatment at $1253 \mathrm{~K}$ or aging (Figures 6(c) and (d)).

In the IN718 alloy, in the as-linear friction welded conditions, secondary particles were dissolved (except for the Laves phase and MC carbides) close to the $\mathrm{WZ}$ due to the LFW temperature (1473 to $1523 \mathrm{~K}$ ), which was higher than the $\gamma^{\prime}$ and $\gamma^{\prime \prime}$ dissolution temperatures $\left(\gamma^{\prime}=1243 \mathrm{~K}\right.$ and $\left.\gamma^{\prime \prime}=1203 \mathrm{~K}\right)$. On the SLM and H-SLM IN718 sides, small particles of the Laves phase dissolved and their constitutional elements ( $\mathrm{Nb}$ and $\mathrm{Mo}$ ) diffused to the $\gamma$ matrix due to high temperatures (1473 to $1523 \mathrm{~K}$ ). For their part, the large Laves particles were partially dissolved and transformed to granular and finer particles since the cooling rate was high and, therefore, the time for the evolution was short. ${ }^{[12,17,57]}$ After the PWHT (both DA and STA samples), very fine $\gamma^{\prime}$ and $\gamma^{\prime \prime}$ precipitated and were observed in IN718 (in both SLM and H-SLM conditions) in all zones. Generally, the same fraction of $\gamma^{\prime} / \gamma^{\prime \prime}$ is expected close to the WZ of W1-DA and W2-DA. However, as we go from the WZ toward the BM, the volume fraction of the $\gamma$ " phase in W2-DA could be significantly higher than in W1-STA, but slightly lower than in W1-DA due to some possible $\gamma^{\prime \prime}$ phase remnants after the SLM process in the microstructure of $\mathrm{W} 1$ (in the BM and almost in the TMAZ). It should be noted that both the Laves phase $(\mathrm{Ni}, \mathrm{Cr}, \mathrm{Fe})_{2}(\mathrm{Nb}, \mathrm{Mo}, \mathrm{Ti})(\mathrm{Nb}-\mathrm{rich})$ and the $\delta$ phase (in W1-STA) $\mathrm{Ni}_{3} \mathrm{Nb}$ ( $\mathrm{Nb}$ and Ti-rich), in W1-STA and W1-DA, can slow the precipitation of the $\gamma^{\prime \prime}$ and $\gamma^{\prime}$ strengthening phases. ${ }^{[13,14]}$ As reported in References 15, 58 and 59 carefully adjusting $\mathrm{Nb}, \mathrm{Ti}$, and $\mathrm{Al}$ is one the most effective ways of controlling the thermal stability and precipitation of $\gamma^{\prime \prime}$ and $\gamma^{\prime}$. The $\delta$ particles were recognized by their morphology and their $\mathrm{Nb}$ and $\mathrm{Ti}$ contents, which were, respectively, lower than those of the Laves particles (Table II). From the EDS results, it 


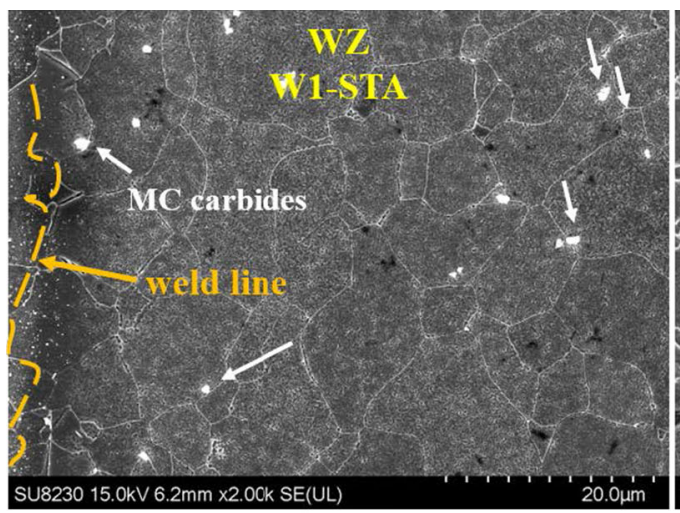

(a)

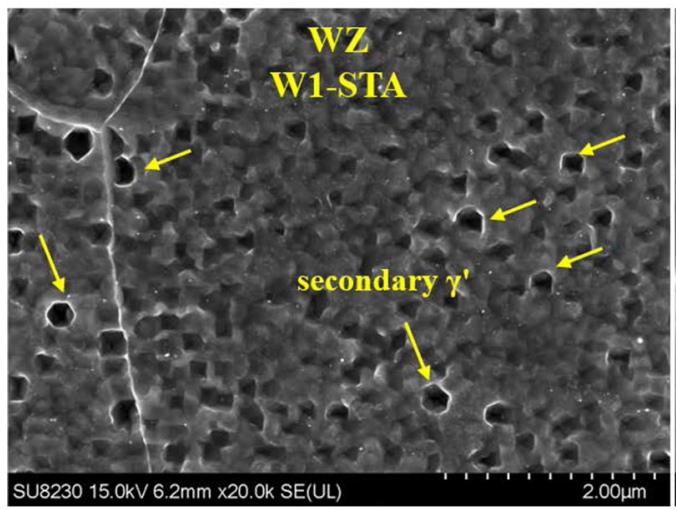

(c)

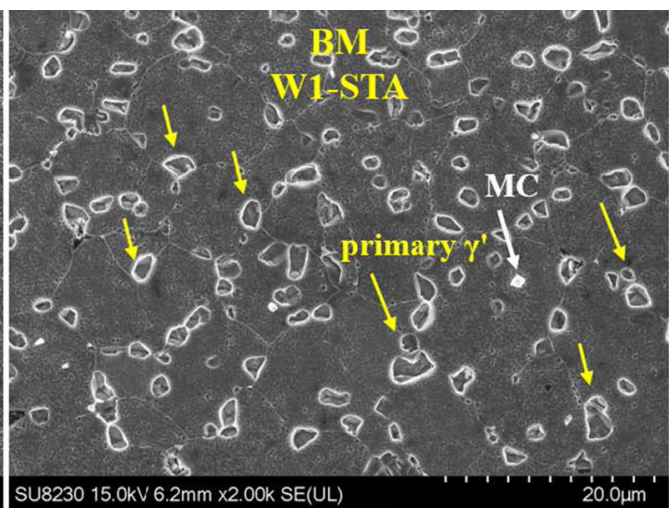

(b)

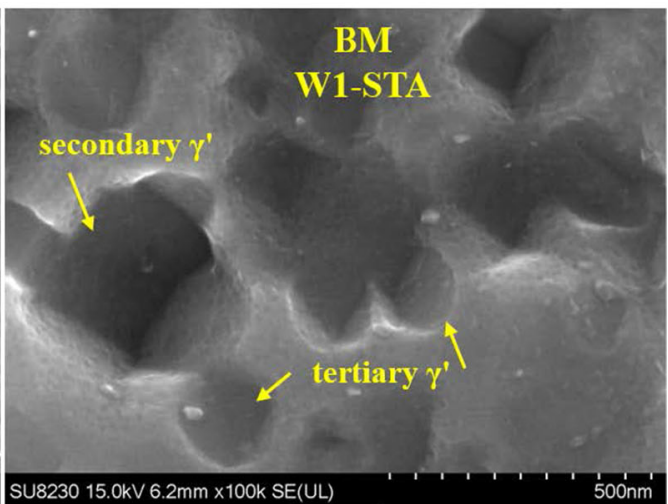

(d)

Fig. 6 - SEM images of $\gamma^{\prime}$ precipitates in sample W1-STA: $(a)$ and $(c)$ in the WZ and $(b)$ and $(d)$ in the BM of AD730 side.

can be seen that the blocky particles close to the weld line are Laves phase due to their lower amounts of $\mathrm{Nb}$ and Ti than MC carbides. ${ }^{[60-62]}$ The Nb concentration in the $\delta$ and in the Laves phases in the TMAZ was higher than in the WZ and lower than in the BM due to the thermomechanical gradient from the WZ to the BM during LFW, which changed the rate and diffusion distance of the elements according to References 12 and. 17

As shown in Figures 8(a) through (i), the Laves phase fraction increased from the weld line toward the BM in all three samples. For example, Figure 8(a) shows that the Laves phase fraction in the BM of the W1-AD sample (on the IN718 side) was more than in the others. In W1-STA (Figures 8(d) through (f)), the remaining Laves particles of as-linear friction welded $\mathrm{W} 1$ were transformed into $\delta$ and $\gamma^{\prime \prime}$ due to the ST and aging treatment, respectively. The W2-DA sample (Figures 8(g) through (i)) contained the lowest amount of Laves particles due to the homogenization treatment that took place before LFW. The evolution of the Laves phase in the W1 and W2 samples at different locations from the weld line to the BM region has been reported in Reference 17. Spherical (or semispherical) Laves particles within the grains in the WZ were transformed to long-striped shapes in the interdendritic regions in the HAZ and BM. Therefore, variations of secondary phases, such as $\gamma^{\prime}, \gamma^{\prime} / \gamma^{\prime \prime}, \delta$, carbides, and Laves, in
IN718 (SLM and H-SLM) and AD730 alloys could provide different mechanical properties for the dissimilar joint.

\section{B. Microhardness}

Figure 9 shows the evolution of the hardness in the post-weld heat treated samples (W1 $\rightarrow$ W1-DA, $\mathrm{W} 1-\mathrm{STA}$, and $\mathrm{W} 2 \rightarrow \mathrm{W} 2-\mathrm{DA})$ and its variation in different regions. Applying the proposed PWHT helped the back diffusion of segregated elements in the Laves particles into the matrix solid solution and precipitation of $\gamma^{\prime}, \gamma^{\prime \prime}$, and $\delta$ phases with the desired morphology in the IN718 alloy. It also induced reprecipitation of $\gamma^{\prime}$ in AD730, thereby allowing for the restoration of the hardness in the weldment, as discussed in detail subsequently. It must be noted that the hardness data for as-linear friction welded conditions (W1 and W2) are reported from a recent publication by the present authors. ${ }^{[17]}$

After PWHT, the hardness increased as compared to that of the as-linear friction welded samples (W1 and W2) in all zones. Table III provides the microhardness comparison values between the PWHT and as-linear friction welded conditions for both alloys in all zones. In order to better illustrate the variations, the data are presented in terms of percentage difference (i.e., $((\mathrm{PWHT}-\mathrm{AW}) / \mathrm{AW}) \times 100)$ in each zone of both alloys. 


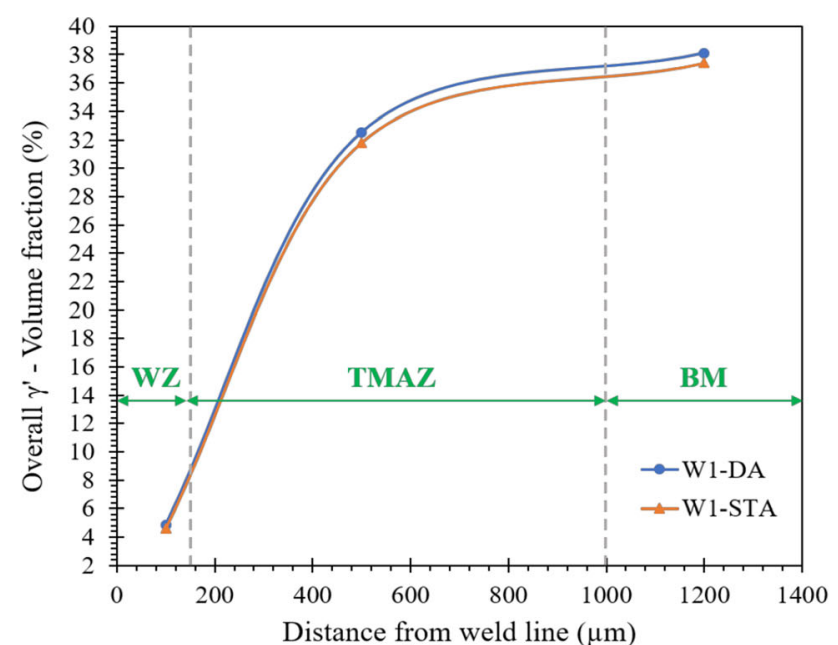

(a)

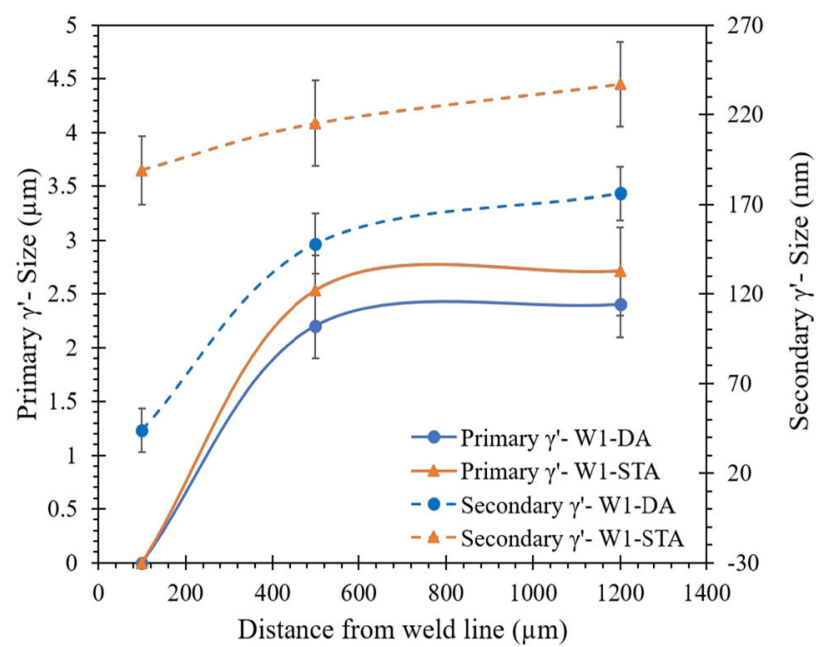

(b)

Fig. 7-Variation of $(a)$ the volume fraction and $(b)$ the size of primary and secondary (and tertiary) $\gamma^{\prime}$ on the AD730 side in W1-DA and W1-STA samples from the weld line to the BM.

Table II. EDS Chemical Composition Analysis of Laves and $\delta$ Phases in the Post-Weld Heat Treated Samples in the TMAZ

\begin{tabular}{rllrlcrr}
\hline & & \multicolumn{6}{c}{ Main Constituent } \\
\cline { 3 - 8 } Phase & Sample & $\mathrm{Ni}$ & $\mathrm{Nb}$ & $\mathrm{Mo}$ & $\mathrm{Ti}$ & $\mathrm{Fe}$ & $\mathrm{Cr}$ \\
\hline Laves & W1-DA & bal & 34.87 & 1.74 & 7.76 & 9.74 & 18.09 \\
& W1-STA & & 20.17 & 1.45 & 2.63 & 5.06 & 8.90 \\
\multirow{4}{*}{$\delta$} & W2-DA & & 17.46 & 1.34 & 3.84 & 13.07 & 16.01 \\
& W1-DA & bal & 9.09 & 2.42 & 8.62 & 15.59 & 9.63 \\
& W1-STA & & 11.10 & 1.14 & 3.97 & 6.52 & 7.19 \\
& W2-DA & & 8.15 & 2.17 & 6.13 & 14.58 & 12.45 \\
\hline
\end{tabular}

Furthermore, in the last two columns of Table III, the hardness differences of post-weld heat treated samples in different locations or between the two alloys are reported.
An overall analysis of the data reported in Table III shows that the highest hardness variation occurred in the WZ of IN718 (90 pct for W2-DA) and in the TMAZ of AD730 (33.5 pct for W1-DA). The minimum change was seen in the WZ of AD730, the BM of IN718 in W1-DA and W1-STA samples, and the TMAZ of IN718 in the W2-DA sample. However, the relative increase in the hardness in the BM zone of IN718 in the W2-DA sample was higher than in all three samples. After PWHT, for each alloy, the maximum difference in the hardness was measured between the $\mathrm{WZ}$ and the $\mathrm{BM}$, as reported in column 7 of Table III. These changes, ranging between 17 are $25 \mathrm{HV}$, are not necessarily related to variations in grain size, as will be discussed subsequently. In the last column of Table III, the maximum hardness difference in the WZ of IN718 and AD730 after PWHT is reported. These data will be used to discuss the influence of microstructural changes during PWHT on hardness evolution in each alloy in the following sections.

On the IN718 side, the increase in the hardness is mainly attributable to the precipitation of $\gamma^{\prime}+\gamma^{\prime \prime}$ as strengthening phases, as well as to the coarsening of precursor $\gamma^{\prime}$ and $\gamma^{\prime \prime}$ particles remaining from the SLM process in W1-DA in the TMAZ and in the BM. In the WZ, the reprecipitation of these phases with a higher volume fraction is generally expected to increase the hardness more than in other zones. Due to the dissolved $\mathrm{Nb}$-rich Laves phase in the WZ, the amount of $\mathrm{Nb}$ (as $\gamma^{\prime \prime}$ forming element) increases in the matrix and enhances the precipitation of $\gamma^{\prime \prime}$ during PWHT. As a result, the volume fraction of $\gamma^{\prime}+\gamma^{\prime \prime}$ could increase in the IN718 alloy; thus, an 83 to 90 pct change in hardness is observed in this zone (Figure 9 and Table III). However, in W1-STA, due to the precipitation of $\delta$ phase during the ST, the $\mathrm{Nb}$ content necessary for precipitation of $\gamma^{\prime \prime}$ decreases in the matrix; hence, a lower fraction of $\gamma^{\prime \prime}$ is expected in W1-STA than in the other two samples, and the change in hardness is less than in them.

Furthermore, as reported in References 7, 40 and 63 the coherent strain strengthening induced by the precipitation of $\gamma^{\prime \prime}$ and $\gamma^{\prime}$ phases is the main strengthening mechanism in the IN718 alloy. Furthermore, it is well known that the mismatch induced by the $\gamma^{\prime \prime}$ phase in the matrix results in a stress field. Dislocation movement also induces the stress in the matrix. Therefore, interactions between these fields can block the dislocation movements and increase the strength of the material. ${ }^{[7,40,64]}$ Therefore, the precipitation of mainly $\gamma^{\prime \prime}$ and $\gamma^{\prime}$ after PWHT and grain refinement ${ }^{[17]}$ and solid-solution strengthening ${ }^{[12,16,17,65,66]}$ could enhance the hardness of the IN718 alloy. Although grain refinement is a mechanism used to increase the hardness in as-linear friction welded conditions (W1 and W2), the grain sizes did not change after PWHT. Therefore, the influence of secondary phases on the mechanical properties of the SLM IN718 should be considered in the present situation.

It is notable that the DA sample (W1-DA) shows the highest hardness (the blue line in Figure 9), although the Laves phase is still observed due to the low aging 


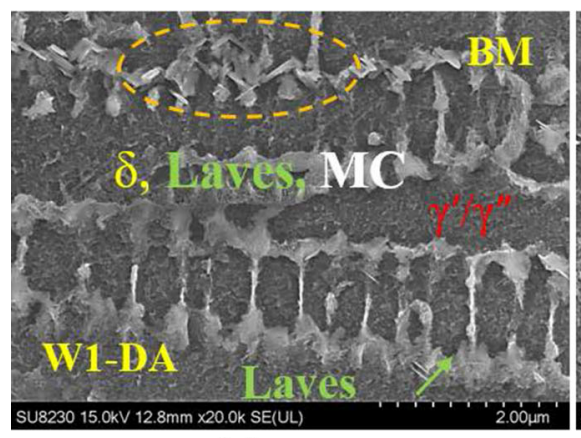

(a)

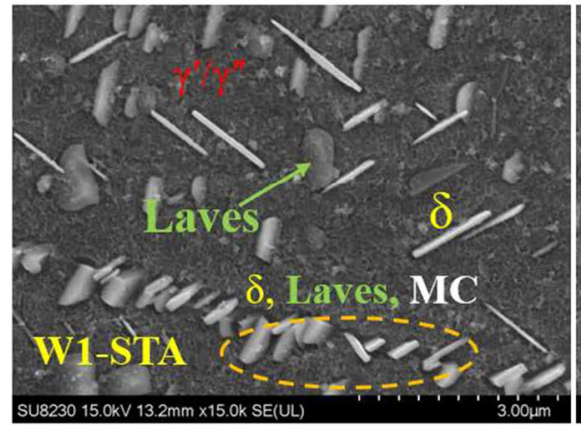

(d)

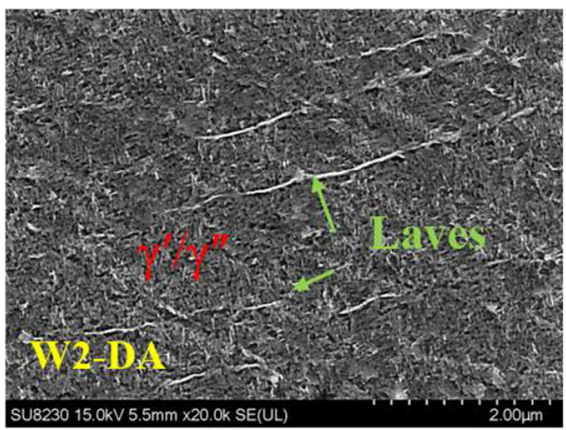

(g)

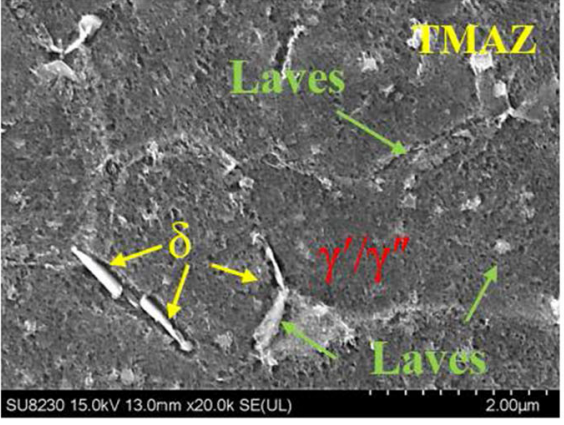

(b)

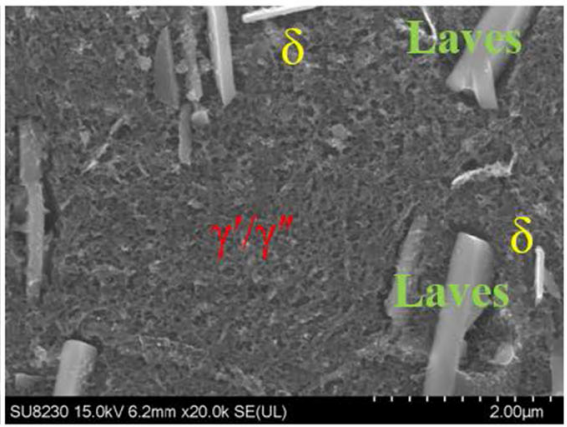

(e)

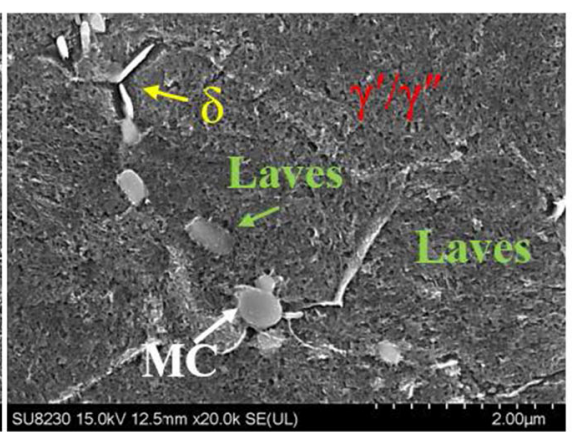

(h)

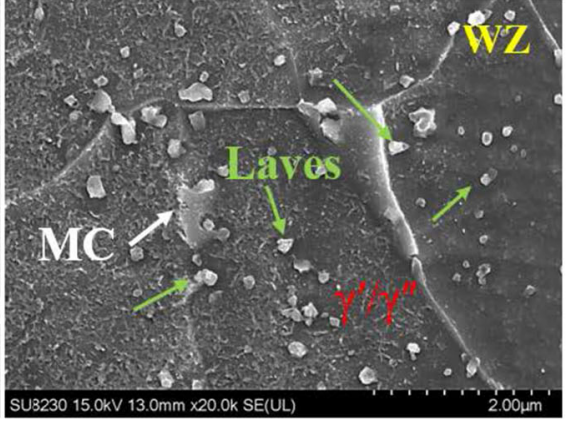

(c)

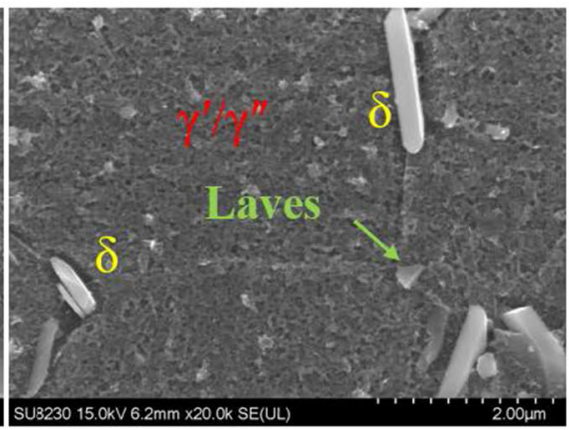

(f)

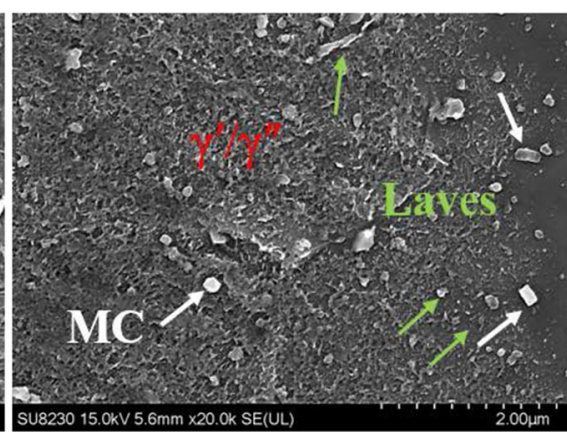

(i)

Fig. 8-Precipitation of secondary phases in the microstructure after the PWHT: $(a)$ through $(c)$ W1-DA, $(d)$ through $(f)$ W1-STA, and $(g)$ through $(i)$ W2-DA on the IN718 (SLM and H-SLM) sides $(a),(d)$, and $(g)$ at the BM, $(b),(e)$, and $(h)$ at the TMAZ, and $(c)$, $(f)$, and $(i)$ at the WZ.

temperature. In W2-DA, due to the homogenization before LFW, the Laves particles could partially be eliminated in the microstructure. However, in W1-STA, the formation of $\delta$ phase (needlelike) was observed close to the Laves phase after heat treatment at $1253 \mathrm{~K}$. This indicates that the $\delta$ phase had precipitated out from the Laves phase dissolution, as also reported in Reference 45. The direct-aged W1-DA sample is expected to have higher ultimate tensile stress but lower elongation than both W1-STA and W2-DA samples. Sui et al. ${ }^{[15]}$ reported that the presence of Laves phases (as in W1-DA) could have a strengthening effect, even if not coherent with the matrix.

Sui et $a l .^{[15]}$ reported that the formation and presence of the Laves phase is accompanied by notable niobium microsegregation, which causes an inhomogeneous distribution and coarsening of $\gamma^{\prime \prime}$ phase. After homogenization on SLM IN718 (i.e., H-SLM in W2), as well as a significant reduction in the volume fraction of the
Laves phase, ${ }^{[12,17]}$ long-striped Laves phases are almost eliminated and transformed into spherical particles, the $\gamma$ " phase distribution becomes uniform, and the residual stress accumulation could decrease. ${ }^{[15,16]}$ Huang et al. ${ }^{[14]}$ and Marchese et al. ${ }^{[67]}$ reported that due to repeated rapid heating and cooling during the SLM process, dislocation density increases. This leads to a gradual increase in the level of residual stresses, which can act as a strain hardening source. Therefore, the dislocation density can remain at a relatively high level after the DA due to low-temperature treatment.

It should be noted that on the IN718 side in W1 (Figure 9, black line), the Laves phase volume fractions were $~ 18.5$ pct and 12 to 15 pct in the BM and the TMAZ, respectively. Prior to the PWHT, the average hardness of this sample in the BM was $\sim 60 \mathrm{HV}$ higher than in the TMAZ. However, after PWHT (Figure 9, blue line), the difference in hardness between the WZ and the TMAZ decreased. This indicates that the 


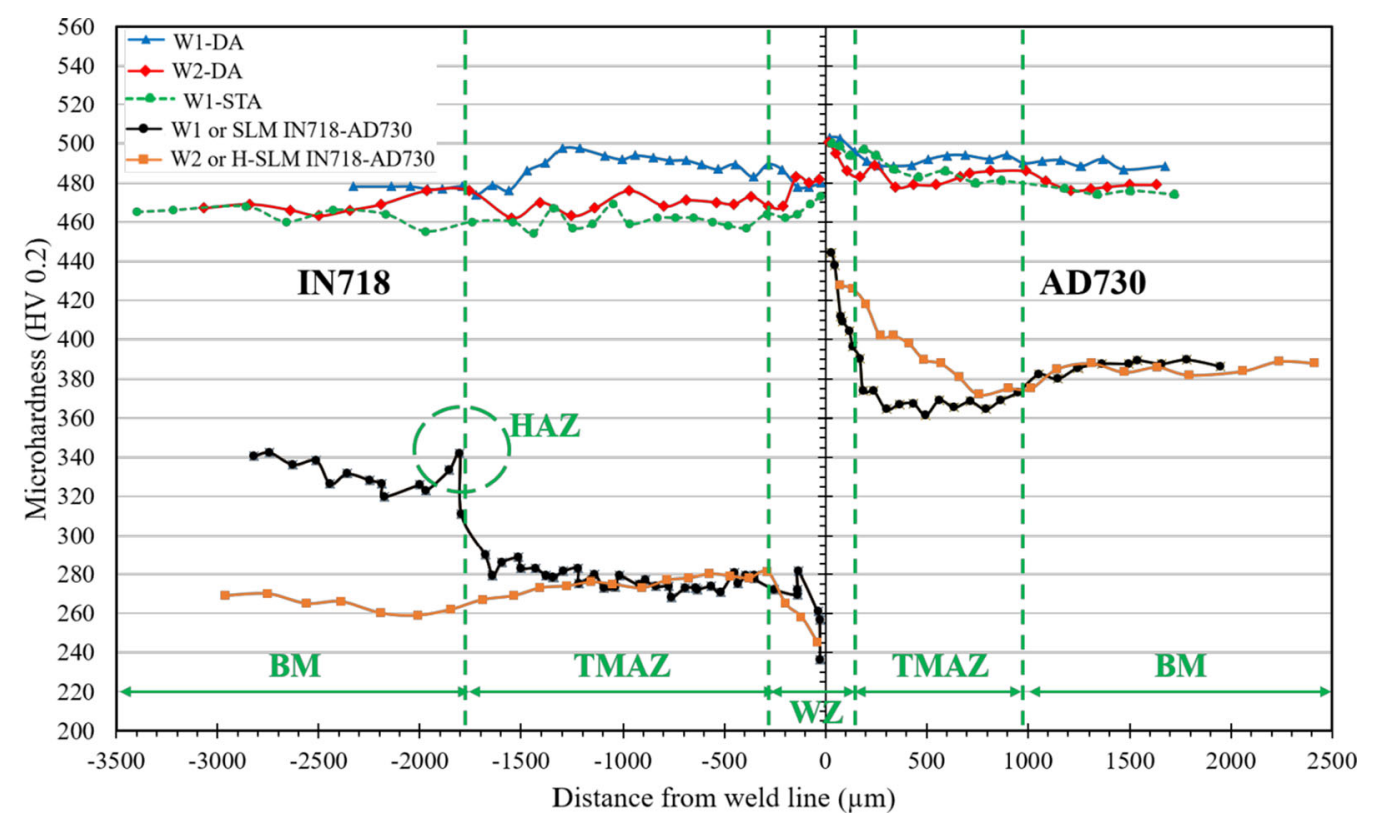

Fig. 9-Microhardness profiles as a function of distance from the weld line of two linear friction welded samples. The hardness profiles of W1 and W2 samples are captioned from Ref. 17.

hardness in the TMAZ was even higher $(\sim 15 \mathrm{HV})$ than the WZ due to the precipitation of $\gamma^{\prime}+\gamma^{\prime \prime}$. The reduction of $\mathrm{Nb}$ content in the Laves phase makes the Laves crystal structure unstable. ${ }^{[57]}$ On the contrary, a high concentration of $\mathrm{Nb}$ will diffuse again into the $\gamma$ matrix and will contribute to the precipitation of $\gamma$ "' and $\delta$ phases $\left(\mathrm{Ni}_{3} \mathrm{Nb}\right)$.

On the AD730 side (Figure 9 and Table III), as mentioned previously, the PWHT restored the hardness in the weld regions. The hardness increased in the $\mathrm{WZ}$ of all samples due to the coarsening of the remaining ultrafine $\gamma^{\prime}$ during PWHT. However, this increase in the hardness was substantial in the TMAZ ( 23 to 33.5 pct in Table III), although the grain size was smaller than in the WZ ( $\sim 5 \mu \mathrm{m}$ in the WZ $v s \sim 25 \mu \mathrm{m}$ in the TMAZ). In the TMAZ, a simultaneous coarsening of the remaining $\gamma^{\prime}$ particles (primary + secondary + tertiary) and $\gamma^{\prime}$ reprecipitation could increase the hardness more than in other zones. Chamanfar ${ }^{[68]}$ reported that primary $\gamma^{\prime}$ particles remain at the grain boundaries of Waspaloy during thermomechanical processing and inhibit grain growth. In contrast, Huang et al. ${ }^{[2]}$ reported that the presence of the intragranular secondary and tertiary $\gamma^{\prime \prime}$ particles are the main reasons for the higher strength of the 720Li alloy as compared to IN718. The hardness increases to a maximum value with increasing particle size and then it declines. This maximum value was referred to as the "strongest size," which depends on the $\gamma^{\prime}$ volume fraction. ${ }^{[68,69]}$ The preceding behavior was also observed in the BM as compared to the WZ, as also reported in Reference 18 in the case of an LFW of AD730.

Wrought superalloys, such as Waspaloy and AD730, are prone to reheat cracking during PWHT. The higher the $\gamma^{\prime}$ content or the concentration of $\gamma^{\prime}$ forming elements, the higher will be the susceptibility to reheat cracking. ${ }^{[1,24]}$ However, the HAZ was not observed in the as-linear friction welded samples. Besides, no depletion of the matrix from $\gamma^{\prime}$ forming elements related to $\gamma^{\prime}$ precipitation during PWHT was observed due to the application of subsolvus heat treatment.

As reported in the last column in Table III, the difference in hardness between the two alloys after PWHT was around $19 \mathrm{HV}$ for W1-DA and W2-DA in the WZ. This difference was higher $(27 \mathrm{HV})$ in W1-STA due to the stress relief in the WZ and the dissolution of Laves phase by Laves $+\gamma$ (in W1) $\rightarrow$ Laves $+\delta+\gamma$ during the ST. The preceding results could be compared with those reported on dissimilar friction welding of IFW IN718-U720 $\mathrm{Li}^{[22]}$ linear friction welded IN718-IN713LC, ${ }^{[7]}$ and IFW IN718-INCOLOY $909 ;{ }^{[31]}$ the hardness differences between the two alloys were $65 \mathrm{HV}$ (WZ and $\mathrm{BM}), 12 \mathrm{HV}$ (WZ and $\mathrm{BM}$ ), and $28 \mathrm{HV}$ (for WZ) and $60 \mathrm{HV}$ (for BM), respectively. It must be noted that the preceding results were obtained after applying one-step aging for PWHT. However, interestingly, hardness measurements in all zones across the weldments, after the proposed two-step aging, show that the maximum homogeneity occurred on both alloys of the W1- DA sample (Table III) (average of $17 \mathrm{HV}$ for AD730 and 15 HV for SLM IN718 between the WZ and the BM). The hardness differences between the WZ and BM were compared with those published in the literature and are summarized in the following (Figure 10).

(1) IN718-U720Li: ${ }^{[22]} \sim 48 \mathrm{HV}$ for IN718 and $\sim 45$ HV for U720Li.

(2) IN718-IN713LC: ${ }^{[7]} \sim 70 \mathrm{HV}$ for IN718 and $\sim 120$ HV for IN713LC.

(3) IN718-INCOLOY 909:[31] $68 \mathrm{HV}$ for IN718 and $\sim 100 \mathrm{HV}$ for INCOLOY 909.

(4) Although the maximum hardness ( in the WZ) in post-weld heat treated SLM-IN718 in the W1-DA 
Table III. Microhardness Comparisons between Post-Weld Heat Treated and As-Linear Friction Welded Samples in Different Zones

\begin{tabular}{llllllcc}
\hline $\begin{array}{l}\text { PWHT/ } \\
\text { AW }\end{array}$ & Alloy & $\begin{array}{c}\text { WZ } \\
\text { (Pct) }\end{array}$ & $\begin{array}{c}\text { TMAZ } \\
\text { (Pct) }\end{array}$ & $\begin{array}{c}\text { HAZ } \\
\text { (Pct) }\end{array}$ & $\begin{array}{c}\text { BM } \\
(\text { Pct })\end{array}$ & $\begin{array}{c}\text { Max. Difference at Post-Weld } \\
\text { Heat Treated Zones (HV) }\end{array}$ & $\begin{array}{c}\text { Max. Difference in Hardness between } \\
\text { Post-Weld Heat Treated Alloys (HV) }\end{array}$ \\
\hline W1-DA/ & IN718 & 88.2 & 78 & 42 & 46.5 & $17($ WZ-BM) & $19($ WZ) \\
W1 & AD730 & 13.5 & 33.5 & - & 26.1 & $15($ WZ-BM) & $27($ WZ) \\
W1-STA/ & IN718 & 83 & 65 & - & 41.6 & $10($ WZ-BM) & $18($ WZ) \\
W1 & AD730 & 12.6 & 31.4 & - & 22.7 & $24($ WZ-BM) & $20($ WZ-BM) \\
W2-DA/ & IN718 & 90 & 70 & - & 73 & $25($ WZ-BM $)$ & \\
W2 & AD730 & 17 & 23 & - & 25.3 & & \\
\hline
\end{tabular}

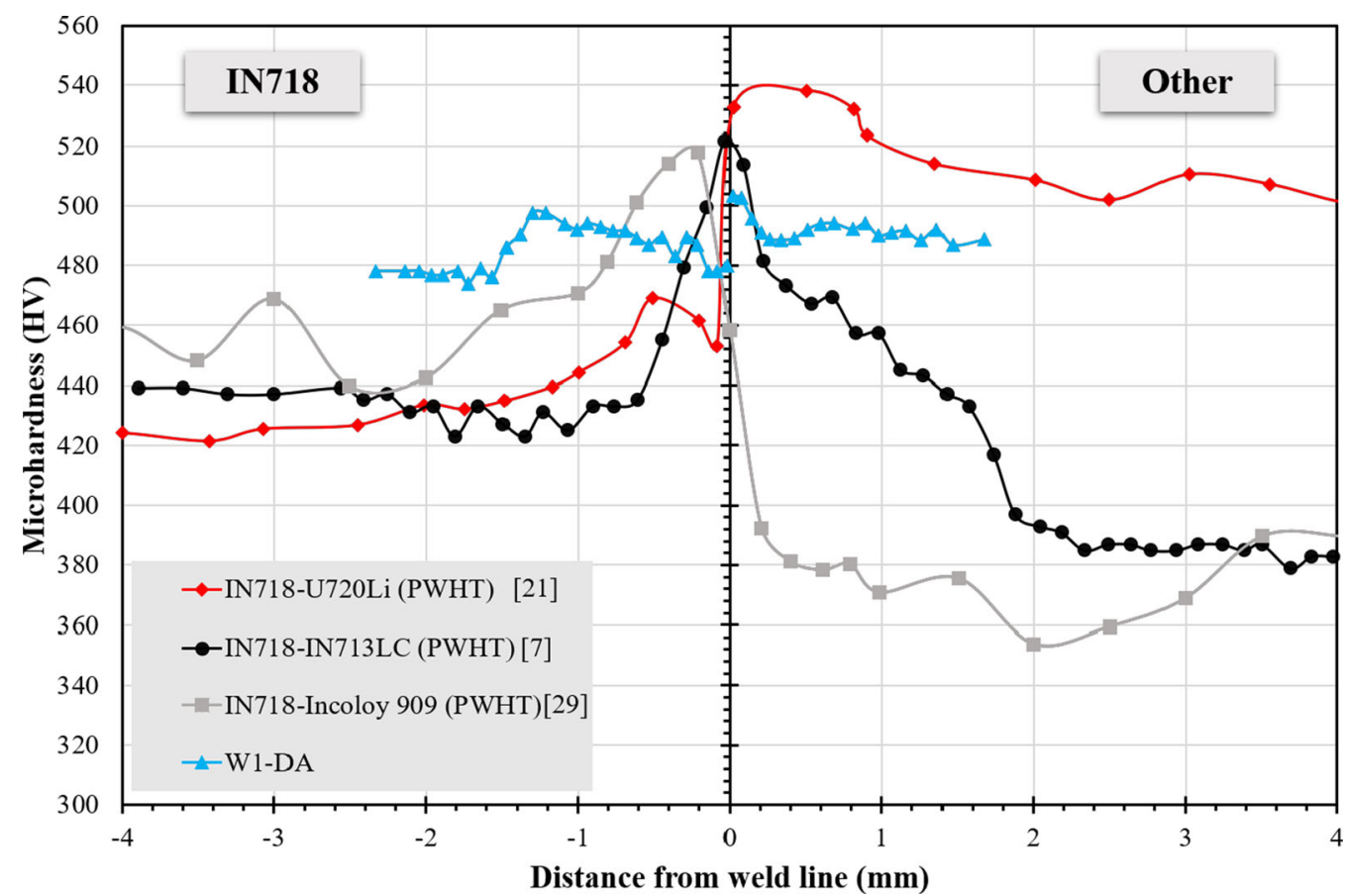

Fig. 10-Hardness distribution across the weld interface in three other dissimilar joints after PWHT.

sample was smaller (30 to $40 \mathrm{HV}$ ) than in other weldments, the hardness was more homogenous on the side of IN718 in W1-DA.

Therefore, applying two-step aging on the LFWs of dissimilar superalloys could provide more homogeneity to the hardness of each alloy and to the weldment. A more homogenous microstructure after the PWHT could potentially provide more isotropic mechanical properties in the joint. In addition to homogeneity, the presence of $\delta$ phase within grain boundaries of IN718 alloy in W1-STA and a larger grain size in W2 and W1-STA (in both alloys) can improve creep resistance. Masoumi et al. ${ }^{[32]}$ reported that a specific PWHT (solutionizing at $1173 \mathrm{~K}$ for 2 hours and aging at 1003 $\mathrm{K}$ for 8 hours) on a linear friction welded fine grain AD73 alloy resulted in a creep strength that was superior to that of as-linear friction welded joints.

\section{CONCLUSIONS}

In this study, PWHT cycles were carried out on linear friction welded dissimilar Ni-based superalloys fabricated by two different methods. The phase transformation and evolution of secondary phases across the weld line were studied following PWHT. The impact of the microstructure evolution on the microhardness variation was also evaluated. The main findings can be summarized as follows.

1. The presence of ultrafine $\gamma^{\prime}$ particles in the $\mathrm{WZ}$ of AD730 alloy in as-linear friction welded samples was revealed, and the particles coarsened during PWHT.

2. The precipitation of the $\gamma$ " phase in post-weld heat treated SLM and H-SLM IN718 (W1-DA and W2-DA) is the main mechanism used to increase the hardness on the side of IN718 alloy. 
3. A comparison of hardness measurements in W1-DA with W1-STA and their microstructure evolution from the WZ to the BM shows that stress relief can be induced by the PWHT cycle and likely reduce the amount of the Laves phase in the microstructure of SLM IN718. However, the hardness in W2-DA (on IN718 side) was greater $(\sim 14$ $\mathrm{HV}$ ) than in the W1-STA in the TMAZ, which can be attributed to the participation of $\mathrm{Nb}$ in the $\delta$ phase formation after ST (i.e., constitutional elements of Laves phase diffused into the $\gamma$ matrix during homogenization in W2). Hence, less Nb was available for $\gamma$ "' precipitation during aging.

4. A double aging cycle based on the precipitation temperatures of the secondary phases in both alloys caused a more homogenous hardness in the joint as compared to the one-step aging previously reported in the literature.

\section{ACKNOWLEDGMENTS}

The authors gratefully acknowledge the support from the Natural Sciences and Engineering Research Council of Canada (NSERC) 2018-03889 through a discovery grant. Thanks to Professor Mamoun Medraj and Dr. Eslam Fayed, Concordia University, for their involvement with the heat treatment of the welded samples. The authors also express their gratitude to Aubert \& Duval Co. and Dr. Alexandre Devaux for providing forged AD730 samples. Technical support provided by Dr. Mohammad Saadati for microscopic experiments is gratefully acknowledged. The authors extend special thanks to TWI Ltd for carrying out the LFW of the samples.

\section{REFERENCES}

1. A. Chamanfar, M. Jahazi, and J. Cormier: Metall. Mater. Trans. $A, 2015$, vol. 46A, pp. 1639-69.

2. I. Bhamji, M. Preuss, P.L. Threadgill, and A.C. Addison: Mater. Sci. Technol., 2011, vol. 27, pp. 2-12.

3. A.C. Addison: TWI Ltd, Cambridge, United Kingdom, 2010.

4. P. Wanjara and M. Jahazi: Metall. Mater. Trans. A, 2005, vol. 36 A, pp. 2149-64.

5. F. Masoumi, D. Shahriari, M. Jahazi, J. Cormier, and B.C.D. Flipo: Metall. Mater. Trans. A, 2017, vol. 48A, pp. 2886-99.

6. X. Cao, B. Rivaux, M. Jahazi, J. Cuddy, and A. Birur: J. Mater. Sci., 2009, vol. 44, pp. 4557-71.

7. R.R. Ye, H.Y. Li, R.G. Ding, T.J.A. Doel, S. Bray, A. Walpole, and P. Bowen: Mater. Sci. Eng.: A, 2020, vol. 774, p. 138894.

8. E. Herderick: Mater. Sci. Technol., 2011, vol. 2, pp. 1413-25.

9. Y. Chen, K. Zhang, J. Huang, S.R.E. Hosseini, and Z. Li: Mater. Des., 2016, vol. 90 , pp. 586-94.

10. K. Moussaoui, W. Rubio, M. Mousseigne, T. Sultan, and F. Rezai: Mater. Sci. Eng. A, 2018, vol. 735, pp. 182-90.

11. V.A. Popovich, E.V. Borisov, A.A. Popovich, V.S. Sufiiarov, D.V. Masaylo, and L. Alzina: Mater. Des., 2017, vol. 131, pp. $12-22$.
12. S. Tabaie, F. Rézaï-Aria, and M. Jahazi: Metals, 2020, vol. 10, pp. 587-608

13. M. Ni, S. Liu, C. Chen, R. Li, X. Zhang, and K. Zhou: Mater. Sci. Eng. A, 2019, vol. 748, pp. 275-85.

14. W. Huang, J. Yang, H. Yang, G. Jing, Z. Wang, and X. Zeng: Mater. Sci. Eng. A, 2019, vol. 750, pp. 98-107.

15. S. Sui, H. Tan, J. Chen, C. Zhong, Z. Li, W. Fan, A. Gasser, and W. Huang: Acta Mater., 2019, vol. 164, pp. 413-27.

16. E.M. Fayed, M. Saadati, D. Shahriari, V. Brailovski, M. Jahazi, and M. Medraj: Metals, 2021, vol. 11, pp. 144-71.

17. S. Tabaie, F. Rézaï-Aria, B.C.D. Flipo, and M. Jahazi: Mater. Charact., 2021, vol. 171, p. 110766.

18. F. Masoumi, D. Shahriari, H. Monajati, J. Cormier, B.C.D. Flipo, A. Devaux, and M. Jahazi: Mater. Des., 2019, vol. 183, pp. 108-17.

19. M. Cheepu, V. Muthupandi, and W.S. Che: Mech. Mater., 2018, vol. 877 , pp. $157-62$.

20. A. Astarita, F. Scherillo, M. Curioni, P. Aprea, F. Impero, A. Squillace, and X. Zhou: Mater. Manufact. Processes, 2016, vol. 31, pp. 2115-22.

21. ON Senkov, DW Mahaffey, SL Semiatin, and C Woodward: Metall. Mater. Trans. A, 2014, vol. 45A, pp. 5545-61.

22. Z.W. Huang, H.Y. Li, M. Preuss, M. Karadge, P. Bowen, S. Bray, and G. Baxter: Metall. Mater. Trans. A, 2007, vol. 38A, pp. $1608-20$

23. A. Chamanfar, M. Jahazi, J. Gholipour, P. Wanjara, and S. Yue: Mater. Charact., 2015, vol. 104, pp. 149-61.

24. A. Chamanfar, M. Jahazi, A. Bonakdar, E. Morin, and A. Firoozrai: Mater. Sci. Eng. A, 2015, vol. 642, pp. 230-40.

25. L Sarrat, A Chamanfar, and M. Jahazi: 2012.

26. Y.-S. Kong, M. Cheepu, and D.-G. Kim: Trans. Ind. Inst. Met., 2020, vol. 73, pp. 1449-53.

27. Y. XuXu, W. Li, X. Yang, and Y. Gu: Mater. Sci. Eng.: A, 2020, vol. 788 , p. 139596

28. A. Chamanfar, M. Jahazi, J. Gholipour, P. Wanjara, and S. Yue: Metall. Mater. Trans. A, 2011, vol. 42A, pp. 729-44.

29. R Damodaram, S Ganesh Sundara Raman, DVV Satyanarayana, G Madhusudhan Reddy, and K Prasad Rao: Mater. Sci. Eng. A, 2014, vol. 612, pp. 414-22.

30. G. Qin, P. Geng, J. Zhou, and Z. Zou: Mater. Des., 2019, vol. 172, p. 107766

31. O. Roder, D. Helm, S. Neft, J. Albrecht, and G. Luetjering: Proceedings of the Sixth International Special Emphasis Symposium on Superalloy, 2005, pp. 649-58.

32. F. Masoumi, L. Thébaud, D. Shahriari, M. Jahazi, J. Cormier, A. Devaux, and B.C.D. Flipo: Mater. Sci. Eng. A, 2018, vol. 710, pp. 214-26.

33. F. Masoumi, D. Shahriari, M. Jahazi, J. Cormier, and A. Devaux: Sci. Rep., 2016, vol. 6, p. 28650

34. M. Panella, L. Signor, J. Cormier, M. Bernacki, and P. Villechaise: Superalloys, Springer, Cham, 2020, pp. 570-78.

35. M. Smith, L. Bichler, J. Gholipour, and P. Wanjara: Int. J. Adv. Manufact. Technol., 2017, vol. 90, pp. 1931-46.

36. M. Smith, L. Bichler, and D. Sediako: Mater. Sci. Forum, 2016, vol. 879 , pp. $1800-06$.

37. M.C. Chaturvedi: Mater. Sci. Forum, 2007, vols. 546-549, pp. 1163-70.

38. MC Chaturvedi and Y Han: Met. Sci., 1983, vol. 17, pp. 145-49.

39. Y.-L. Kuo, S. Horikawa, and K. Kakehi: Mater. Des., 2017, vol. 116, pp. 411-18.

40. L.S. Ling, Z. Yin, Z. Hu, J.H. Liang, Z.Y. Wang, J. Wang, and B.D. Sun: Materials (Basel), 2019, vol. 13, pp. 151-65.

41. W. Cao: Superalloys, 2008, pp. 789-97.

42. M. Rafiei, H. Mirzadeh, and M. Malekan: Vacuum, 2021, vol. 184, p. 109913

43. S. Katnagallu, S. Vernier, M.-A. Charpagne, B. Gault, N. Bozzolo, and P. Kontis: Scripta Mater., 2021, vol. 191, pp. 7-11.

44. M. Pérez, C. Dumont, O. Nodin, and S. Nouveau: Mater. Charact., 2018, vol. 146, pp. 169-81.

45. M.J. Sohrabi and H. Mirzadeh: Mater. Lett., 2020, vol. 261, p. 127008 .

46. H.Y. Zhang, S.H. Zhang, M. Cheng, and Z.X. Li: Mater. Charact., 2010, vol. 61, pp. 49-53. 
47. A. Chamanfar, M. Jahazi, J. Gholipour, P. Wanjara, and S. Yue: Mater. Sci. Eng. A, 2012, vol. 555, pp. 117-30.

48. A. Chamanfar, M. Jahazi, J. Gholipour, P. Wanjara, and S. Yue: Metall. Mater. Trans. A, 2013, vol. 44A, pp. 4230-38.

49. H.-y. Gan, M. Cheng, Z.-x. Guo, Q.-a. Tai, G. Kozhevnikova, H.-w. Song, and S.-h. Zhang: J. Mater. Eng. Perform., 2020, vol. 29 , pp. $3852-57$.

50. P. Geng, G. Qin, T. Li, J. Zhou, Z. Zou, and F. Yang: J. Manuf. Processes, 2019, vol. 45, pp. 100-14.

51. F. Masoumi, M. Jahazi, D. Shahriari, and J. Cormier: J. Alloys Compd., 2016, vol. 658, pp. 981-95.

52. I.M. Lifshitz and V.V. Slyozov: J. Phys. Chem. Solids, 1961, vol. 19 , pp. $35-50$.

53. A. Devaux, L. Nazé, R. Molins, A. Pineau, A. Organista, J.Y. Guédou, J.F. Uginet, and P. Héritier: Mater. Sci. Eng. A, 2008, vol. 486, pp. 117-22.

54. S. Zhang, X. Lin, L. Wang, X. Yu, H. Yang, L. Lei, and W. Huang: Mater. Sci. Eng.: A, 2021, vol. 803, p. 140702.

55. R.A. Ricks, A.J. Porter, and R.C. Ecob: Acta Metall., 1983, vol. 31, pp. 43-53.

56. T. Grosdidier, A. Hazotte, and A. Simon: Mater. Sci. Eng. A, 1998, vol. 256, pp. 183-96.

57. F. Liu, F. Lyu, F. Liu, X. Lin, and C. Huang: J. Mater. Res. Technol., 2020, vol. 9, pp. 9753-65.

58. B. Hassan and J. Corney: Mater. Sci. Technol., 2017, vol. 33, pp. 1879-89.

59. XS Xie, SH Fu, SQ Zhao, and JX Dong: Mater. Sci. Forum, 2010, vols. 638-642, pp. 2363-68.
60. S. Vernier, A. Pugliara, B. Viguier, E. Andrieu, and L. Laffont: Metall. Mater. Trans. A, 2020, vol. 51A, pp. 6607-29.

61. A. Mitchell, A.J. Schmalz, C. Schvezov, and S. Cockroft: in Superalloys 718, 625 and Various Derivatives, E.A. Loria, ed., TMS-AIME, Warrendale, PA, 1994, pp. 65-78.

62. A. Mitchell: Superalloys 718, 625, 706 and Various Derivatives (2005), 2005, pp. 299-310.

63. R.Y. Zhang, H.L. Qin, Z.N. Bi, J. Li, S. Paul, T.L. Lee, S.Y. Zhang, J. Zhang, and H.B. Dong: Metall. Mater. Trans. A, 2020, vol. 51A, pp. 1860-73.

64. J. Cormier, P. Gadaud, M. Czaplicki, R.Y. Zhang, H.B. Dong, T.M. Smith, F. Zhang, J.S. Tiley, and S.L. Semiatin: Metall. Mater. Trans. A, 2020, vol. 51A, pp. 500-11.

65. T.J. Ma, L.F. Tang, W.Y. Li, Y. Zhang, Y. Xiao, and A. Vairis: $J$. Manuf. Processes, 2018, vol. 34, pp. 442-50.

66. A. Harte, M. Atkinson, A. Smith, C. Drouven, S. Zaefferer, J. Quinta da Fonseca, and M. Preuss: Acta Mater., 2020, vol. 194, pp. $257-75$.

67. G. Marchese, E. Atzeni, A. Salmi, and S.. Biamino: J. Mater. Eng. Perform., 2020, vol. 30, pp. 565-74.

68. A. Chamanfar: Mining and Materials Engineering, McGill University, Montreal, 2012.

69. M.P. Jackson and R.C. Reed: Mater. Sci. Eng. A, 1999, vol. 259, pp. 85-97. 